\title{
CONSIDERACIONES SOBRE LOS DELITOS ECONÓMICOS EN EL COMERCIO EXTERIOR COSTARRICENSE
}

\author{
VELIA GOVAERE VICARIOLI \\ Observatorio de Comercio Exterior \\ Universidad Estatal a Distancia, Costa Rica \\ vgovaere@gmail.com
}

\section{RESUMEN}

El presente artículo analiza, posiblemente por primera vez, el impacto del derecho penal económico aplicado al andamiaje jurídico, institucional y administrativo del comercio exterior costarricense, expresado en áreas temáticas del comercio exterior administradas por la plétora de entidades vinculadas a esta materia. La aplicación del derecho penal económico al comercio exterior costarricense es expresión de la tutela del buen funcionamiento del ordenamiento económico, en una amplia gama de bienes jurídicos y contempla la defensa de los intereses de los administrados para accionar, tanto bajo las normas del comercio internacional, como bajo la legislación ordinaria doméstica. Este recorrido panorámico de nuestro comercio exterior visto a la luz de las violaciones al derecho penal económico nos ilustra su desempeño, sus carencias, sus duplicidades y muchas veces, la necesidad de ir mejorando el entorno legal e institucional concerniente a las diversas áreas del comercio exterior en Costa Rica.

PALABRAS CLAVES: DERECHO PENAL ECONÓMICO, COMERCIO EXTERIOR, DELITOS ECONÓMICOS.

\section{ABSTRACT}

This article analyzes, possibly for the first time, the impact of economic criminal law on the legal, institutional and administrative arrangements of Costa Rican foreign trade, as expressed in thematic areas of foreign trade that are managed by a plethora of entities. The application of economic criminal law to Costa Rican foreign trade is an expression of the tutelage of the proper functioning of the economic order, in a broad range of legal goods, and comprises the defense of the interests of those who are managed to act under the norms of both international law and ordinary domestic law. This panoramic overview of our foreign trade viewed from the standpoint of violations of economic criminal law illustrates its performance, its shortcomings, its duplications and often the need to improve the legal and institutional environment that is concerned with the broad area of foreign trade in Costa Rica.

KEYWORDS: ECONOMIC CRIMINAL LAW, FOREIGN TRADE, ECONOMIC CRIMES.

\section{INTRODUCCIÓN}

El comercio exterior es un área temática específica sujeta al ordenamiento jurídico costarricense, con tutelas específicas de gran trascendencia administrativa, social, económica y productiva del sistema económico costarricense. El volumen inmenso de riquezas que se mueve en ese ámbito hace este campo particularmente susceptible a la actividad delictiva. La importancia de enfrentar con éxito y eficacia el delito económico en el campo del comercio exterior, responde tanto a la necesidad doméstica de efectividad de la legislación interna, como a la obligación de cumplir con compromisos de Estado a nivel internacional, implícitos en los cuerpos jurídicos que le dan origen a su normativa. 
Bajo nuestro ordenamiento jurídico, los compromisos internacionales asumidos por el país, una vez completado el proceso de incorporación al ordenamiento interno, crean derechos y deberes, tanto para el Estado costarricense como para los administrados (nacionales o extranjeros), que deben ser tutelados. Es así que la incorporación de los acuerdos internacionales comerciales, generan derechos y deberes para el Estado costarricense y, por otro lado, el ordenamiento jurídico costarricense crea la posibilidad para los administrados de defender derechos emanados de los acuerdos internacionales incorporados en nuestra legislación doméstica.

El derecho comercial internacional se aplica vía procedimientos basados en reglas, principios y códigos de conducta pre-establecidos de forma vinculante y debidamente sancionados por ley. El comercio entre Estados forma un dominio jurídico que es parte inherente tanto de las legislaciones internas de los países, como del derecho internacional público. El sujeto de derecho aquí referido pueden ser tanto personas físicas y jurídicas como Estados nacionales.

La complejidad de la materia de comercio exterior, tanto en su aspecto administrativo como en su base técnica material y su amplia importancia económica hace que el derecho directamente relacionado con el comercio internacional tenga regulación propia. Su amplio ámbito de aplicación necesita otorgar competencias específicas a órganos especializados del Estado, situando su legislación dentro del principio del ejercicio inter-orgánico de las funciones del Estado, donde diferentes entidades públicas tienen bajo su cargo diversas áreas temáticas, planteando en cada acto de administración de comercio el entramado del carácter interorgánico de la Administración Pública. Esto implica, además, que dentro de la amplia gama de competencias otorgadas a las diferentes instituciones, los administrados pueden accionar para la defensa de sus intereses, ya que están jurídicamente protegidos tanto bajo las normas del comercio internacional interiorizadas, como bajo la legislación ordinaria doméstica, en estamentos administrados por diversas entidades públicas.

El derecho penal económico es un estamento específico del derecho penal, que bajo una aceptación amplia protege el orden económico establecido bajo los preceptos constitucionales. Bajo esta orientación, Henry Issa (2004) señala que los delitos económicos pueden agrupar "... todos los ilícitos que por su modo de realización o por el perjuicio que producen puedan atentar o poner en grave peligro la estabilidad económica o hacer desaparecer la confianza del público en la honestidad de las prácticas comerciales o en el buen funcionamiento de las instituciones públicas relacionadas con la economía" (Issa, 2004, p.5). Agrega este autor como, la violación a bienes jurídicos expresamente tutelados por preceptos constitucionales, deben considerarse bajo la legislación penal y asegura que, "... las acciones que violen estos postulados son sancionadas de manera rigurosa por la ley penal, pues son, por autonomasia, delitos económicos, por violar derechos fundamentales" (Issa, 2004, p.6)

Así la aplicación del derecho penal económico al comercio exterior costarricense, es expresión de la tutela del buen funcionamiento del ordenamiento económico, en una amplia gama de bienes jurídicos expresamente tutelados en la Constitución Política de Costa Rica como lo son, por particular, la protección debida al estímulo de la producción nacional (art. 50); la protección de la salud, la seguridad y los intereses de los consumidores (art. 46); el derecho de los consumidores a información adecuada y veraz (art.46); la tutela de la confianza en el sistema económico y, en general y en última instancia, la satisfacción de las necesidades de nuestra población a través del más adecuado reparto 
de la riqueza (art.50), directamente ligado a la reasignación de los ingresos percibidos por el Estado, por vía tributaria y aduanera.

Esta relación de los delitos económicos en nuestro comercio exterior se ilustra tanto a través de sentencias judiciales, sentencias de órganos especializados como el Tribunal Aduanero Nacional, sentencias de la Sala Constitucional como del quehacer ligado al derecho administrativo a través de votos de la Comisión Nacional del Consumidor.

El presente artículo analiza el impacto del derecho penal económico aplicado al andamiaje jurídico, institucional y administrativo del comercio exterior costarricense, expresado en áreas temáticas del comercio exterior administradas por la plétora de entidades vinculadas a esta materia. Este ejercicio se aboca a estudiar la aplicación del derecho penal económico, tanto en el desarrollo del modelo de apertura comercial costarricense como en la implementación del comercio exterior a través de los procedimientos administrativos relacionados con diversas áreas temáticas del derecho comercial internacional en Costa Rica.

Se analizarán ejemplos significativos donde el derecho penal económico ha definido y orientado el ámbito de aplicación en materia de administración de comercio. Se estudiarán diversos casos atinentes a la evolución del comercio exterior costarricense, a su implementación de tratados de libre comercio y a su aplicación del comercio exterior a través del entramado de entidades que intervienen en la administración de instrumentos comerciales en el ámbito doméstico costarricense. Este recorrido panorámico de nuestro comercio exterior visto a la luz de las violaciones al derecho penal económico nos ilustra su desempeño, sus carencias, sus duplicidades y muchas veces, la necesidad de ir mejorando el entorno legal e institucional concerniente a las diversas áreas del comercio exterior en Costa Rica.

\section{La importancia de la tutela jurídica en el comercio exterior de Costa Rica}

La tutela jurídica en el comercio exterior de Costa Rica se corresponde con la importancia relativa del comercio internacional dentro del progreso económico del país, así como de su relación con el bienestar de la población. Nuestra Constitución Política refleja un principio de solidaridad en su artículo 50 que establece que "El Estado procurará el mayor bienestar a todos los habitantes del país, organizando y estimulando la producción y el más adecuado reparto de la riqueza" (p. 317). Esto hace que nuestra legislación esté orientada siguiendo el principio de los fines democráticos, sociales y de justicia del Estado. Es de notar, como en este trabajo lo mostraremos, que el principio donde el bien común de la mayoría ha sido defendido contra beneficios de grupos particulares o gremiales, ha sido interpretado en el ámbito de sentencias de la Sala Constitucional en el ámbito del comercio exterior.

Para Costa Rica, desde hace más de 25 años, el comercio internacional es el eje central de su política de desarrollo. El modelo de apertura comercial ha guiado la inserción de Costa Rica a un mundo globalizado, marcando la transición de una economía de exportación de pocos cultivos bajo el modelo previo de sustitución de importaciones, a una economía diversificada y con acceso preferencial asegurado a los mercados de sus principales socios preferenciales. Para lograrlo, el Estado ha establecido acuerdos comerciales internacionales, ha creado incentivos fiscales a exportaciones y a la inversión y ha diseñado un andamiaje administrativo. La importancia de un funcionamiento fluido del sistema, sin abusos y con la debida sanción de infracciones que aseguren la confianza, nacional y extranjera, se deriva del lugar que ha llegado a ocupar el comercio en la generación de riqueza del país. 
El comercio exterior de mercancías ya representaba, en el 2010, más del 60\% del PIB costarricense. Si sumamos el segmento de servicios, el comercio exterior en nuestro país representa más del $80 \%$ de nuestro PIB. Nuestras exportaciones han crecido en promedio un $10 \%$ en las últimas dos décadas, con una diversificación de nuestra oferta exportable de más de 4500 productos a más de 145 destinos del mundo. Y resultado, de una política pública de fomento de Inversión Extranjera y nuestra propia capacidad nacional de atraer inversiones de alta tecnología, Costa Rica es, hoy, el primer exportador per cápita de bienes en América Latina, excluyendo minerales y combustibles y cuarto país del mundo entre aquellos con mayor proporción de exportaciones de alta tecnología dentro de sus exportaciones industriales. Este importante desempeño se traduce en crecimiento de exportaciones, diversificación de productos y destinos y una política de atracción de inversión extranjera de tecnología de punta (Govaere, 2014).

Costa Rica dispone de una de las más sólidas plataformas de comercio exterior en Latinoamérica con acceso preferencial a sus socios comerciales más importantes. Con la aprobación del Acuerdo de Asociación con la Unión Europea, que representa nuestro segundo destino de exportación, con la aprobación legislativa de los TLC con Singapur y con Perú, el 83\% de nuestro comercio internacional estará cubierto bajo el tratamiento preferencial que confieren Ios TLC.

Cada una de estas bases de expansión económica, actual y futura, son fuente de bienestar social y tienen respaldo también en la tutela económica penal que acompaña cada una de sus regulaciones. Analizaremos, en este artículo, algunos casos de delitos de estafa relacionados con la primera etapa de evolución del comercio en Costa Rica, enmarcada bajo el signo de los Contratos de Exportación y los Cer- tificados de Abono Tributario, subvenciones a la exportación que se han prestado a conocido abuso. También analizaremos infracciones relacionadas con la administración del comercio, bajo diferentes áreas temáticas y a cargo de diversos ministerios.

\section{Delitos relacionados con el funcionamiento del comercio exterior}

A mediados de la década de los ochenta, el país tomó la decisión de sustituir el modelo de sustitución de importaciones por uno basado en la apertura comercial con una clara estrategia basada en la promoción de las exportaciones. Piedra angular de lo que se confirmaría como una larga trayectoria exitosa de apertura comercial, se estableció desde entonces un claro eje ofensivo como prioridad nacional. El exitoso desempeño exportador de Costa Rica es ahora producto de una amplia plataforma comercial y una voluminosa inversión extranjera directa, ambos procesos acumulados en el tiempo.

Dentro de la estrategia de desarrollo con que se ha comprometido este Gobierno la promoción de exportaciones tiene un carácter vital. Estas no sólo son el vehículo para generar divisas sino que bajo el enfoque "Exportaciones para el Desarrollo", se les concibe como el elemento motor que impulsará el desarrollo durante las próximas décadas y que constituirá la piedra angular del desarrollo del cambio estructural de la economía costarricense (COMEX, 1987, p. 5).

Sin embargo, al inicio del cambio de modelo, Costa Rica no contaba con ninguno de estos activos y necesitó promover las exportaciones, particularmente las "no tradicionales", a través de incentivos especiales al esfuerzo de las empresas nacionales por exportar. Esas iniciales 
políticas públicas, especialmente fiscales, de fomento a las exportaciones fueron un primer impulso al nuevo modelo, pero se prestaron también a grandes casos de delitos de estafa fiscal, ilustrativos de la posibilidad de abuso, siempre presente en una materia recién implementada. Nos referimos con esto a la figura de la estafa en el uso de los Certificados de Abono Tributario (CAT).

Por otra parte, la regulación de conductas en materia de ofensiva comercial tiene como contrapartida la regulación en materia defensiva, tanto de la producción nacional como de los consumidores, que se plasma en el buen funcionamiento de la administración interna del comercio exterior. El andamiaje de la administración del comercio exterior fue visualizada como un todo holístico de institucionales interconectadas, en un sistema articulado e integral. El ordenamiento costarricense asigna, por la vía legal, competencias específicas a algunas entidades públicas para que contribuyan, desde su ámbito específico a la administración de comercio.

El sistema integral de administración de comercio es una función compartida de múltiples actores, en diferentes áreas temáticas: inocuidad de alimentos, ingreso de productos por aduanas, integridad sanitaria y fitosanitaria de productos importados y la legítima defensa de la producción nacional. Todo esto descansa en un sistema articulado de instituciones que coparticipan, como contrapeso defensivo, frente a la política ofensiva comercial del país en la apertura de mercados (Govaere, 2009).

Los casos, aquí seleccionados y analizados, reflejan el necesario aprendizaje del uso de los instrumentos comerciales tanto de la Administración como del Administrado. Un ejemplo de lo primero es un caso del MAG donde se permiten importaciones "con carácter provisional" sin la respectiva certificación de plantas, que es requisito "sine qua non" para poder importar. Otros ejemplos ilustran la tentación en la que incurre el administrado de violentar la norma que se transforman en lección aprendida para la Administración como el cambio de norma de origen en el Caso Helados Sarita. Los casos que se estudiarán reflejan, a su vez, diversas áreas temáticas del comercio exterior, dando idea justa de la magnitud y extensión del eje de administración del comercio, que incluye el ámbito de verificación de mercados en defensa del consumidor.

\section{Delitos económicos relacionados con nuestra política ofensiva a través del abuso de los Certificados de Abono Tributario}

En nuestra historia comercial, luego de los embates causados por la crisis de los ochenta, se diseña una política de reactivación de la economía costarricense, basada en la promoción de las exportaciones, cuyos resultados fueron positivos desde el ángulo de su desempeño: “... las políticas económicas ejecutadas en la segunda mitad de la década de los años ochenta pueden catalogarse de Costa Rica exitosas, pues permitieron un crecimiento de la producción por encima del $4 \%$ anual y de las exportaciones no tradicionales en un 27\% anual" (Sauma y Trejos, p. 341).

Los Certificados de Abono Tributario (CAT) fueron un subsidio estatal reconocido como tal por el GATT, donde se adquirió, como parte del ingreso de Costa Rica en 1990, el compromiso de que sería paulatinamente desmantelado hasta su eliminación en 1999. Los CAT eran instrumentos de promoción de exportaciones concedidos para fomentar exportaciones no tradicionales a las cuales se exoneraban impuestos internos, incluyendo los de renta. 
El artículo 66 de la Ley del Impuesto sobre la Renta, n. 7092 del 21 de abril de 1988, establecía los contratos de exportación como instrumento de promoción a las a las empresas exportadoras de productos no tradicionales que no estuvieran amparados a tratados de libre comercio. El otorgamiento de Certificados de Abono Tributario (CAT) es un beneficio adquirido bajo los contratos de exportación y son esencialmente, títulos al portador, libremente negociables, emitidos por el Banco Central de Costa Rica en moneda nacional, que sirven para el pago de impuestos directos e indirectos y cuya recaudación corresponde al BCCR como cajero del Estado.

Autores señalan que el modelo de apertura comercial estaba ligado a sistemas de incentivos vinculados a fomentar las exportaciones costarricenses, específicamente las no tradicionales. El sistema de incentivos, sin embargo, para otorgar contratos de exportación y certificados de abono tributario, tenía también consecuencias negativas, señaladas por los mismos autores como "... un elevado costo fiscal, una alta concentración de los incentivos en pocas empresas y un estímulo al componente importador de las exportaciones" (Sauma y Trejos, p. 340). Otros especialistas en materia tributaria, incluyendo el exministro Herrero, concuerdan con que una política basada en el otorgamiento de estos certificados constituía un "oneroso sistema de subsidios (...) que buscaba compensar la falta de competitividad de las empresas locales. (Herrera y Monge, 1990 p. 39). Eso no era malo en sí mismo, pero se prestó a abusos muy nocivos para el fisco, para la economía y para la confianza en el sistema económico y comercial.

Más allá del elevado costo fiscal o de la concentración de incentivos en pocas empresas, que acusan estos autores, analizaremos en este acápite varios casos donde la utilización abusiva por parte de los exportadores de los Certi- ficados de Abono Tributario, se constituyó en delitos de estafa en contra del Estado costarricense.

De una consulta personal realizada al Viceministro de Comercio Exterior de la Administración Chinchilla, se extrajeron algunos casos ilustrativos de estafas mediante CAT, con base en los archivos del Ministerio y en consecuente seguimiento de las noticias periodistas correspondientes. Algunos de los casos no llegaron a juicio dado que se resolvieron por la vía de la conciliación mientras que otros condujeron a condenas con penas de prisión por el delito de estafa. Consignamos algunos de los casos que COMEX ha considerado más relevantes en materia de estafa a través de los Certificados de Abono Tributario y posteriormente profundizaremos en dos ejemplos de abuso al sistema de promoción de exportaciones a través del otorgamiento de CATs.

Dentro de la memoria histórica de COMEX destacan los siguientes casos y sus consiguientes resoluciones:

1. Uno de los procesos penales que se tramitó relacionado con la exportación de camarones (se trató en este caso de exportaciones ficticias), fue realizado por los representantes de la empresa Transacciones Oceánicas. Los imputados fueron Adrián Castro Velásquez y Alfredo Acuña Calderón y ambos evitaron el juicio penal al aceptar pagar al Estado \$194 millones en 60 cuotas durante cinco años, a partir de mayo del 2002.

2. Los representantes de la empresa Central de Exportaciones Agroindustriales Cexa, S.A., Germán Gerardo González Campos y Miguel Valverde Mora, fueron condenados en 1999, a 15 y 10 años de prisión, por el delito de estafa al presentar 113 veces facturas duplicadas (los certificados de los CATs estaban duplicados). 
3. Los representantes de Naviera Continental, empresa dedicada a la exportación de frutas y verduras, Óscar Murillo García, Alberto Jiménez Jiménez y Gerardo Miranda Ruiz, fueron sentenciados en el año 2006, a 10 años de prisión dado que se les declaró culpables de 41 delitos de estafa con Certificados de Abono Tributario.

4. Rodolfo Valverde Villalobos, representante de las empresas Desarrollos Pesqueros de Centroamérica S.A. y Exportibun S.A., fue condenado en diciembre del 2000 a 16 años de prisión por el delito de estafa con CATs. Respecto de este caso se pudo identificar el número de expediente penal 98-021989-0042-PE.0

5. El representante de Marina de Exportaciones, Luis Fernando Aguilar Oses, fue condenado a tres años de prisión por estafa con CATs (Gamboa y Ocampo, COMEX, 2014).

En este análisis se analizarán dos sentencias ilustrativas de la comisión del delito de estafa ligados a los Certificados de Abono Tributario. En el primer caso que estudiaremos se declara a Luis Fernando Aguilar Oses, autor responsable del delito de Estafa en la modalidad de delito continuado, en perjuicio del Estado, con imposición de pena de prisión de tres años. Además se declaró con lugar la acción civil resarcitoria y se condenó, en forma solidaria, a Luis Fernando Aguilar Oses y a Marina de Exportaciones S.A. a pagar, a favor del Estado, ciento veintisiete millones ochocientos cincuenta y ocho mil setecientos diez colones a partir de la firmeza de la sentencia n. ${ }^{\circ}$ 439-01 del veintitrés de abril del dos mil uno del Tribunal de Juicio del Primer Circuito Judicial de San José.

En recurso de casación interpuesto posteriormente en el 2002 se retoman los siguientes hechos que se imputan en este caso y que ilus- tran el delito de estafa mediante beneficio de una exención tributaria (bajo CAT) derivada de exportaciones ficticias:

(...)los agentes del Organismo de Investigación Judicial realizaron las inspecciones in situ y determinaron que en las instalaciones de MAREX S.A. y algunos de sus proveedores no existían las condiciones mínimas de infraestructura para la comercialización viable de los productos marinos, (...) ni para manejar un volumen de operaciones económicamente significativo lo que deviene de sus solicitudes de CAT ante la oficina respectiva del Banco Central (...) EI OIJ derivó válidamente que nunca existió la estructura o soporte necesario para corroborar las ventas de peces y mariscos al extranjero, sino más bien, se desarrolló por parte del acusado y sus coautores, una burda fachada a fin de semejar la presencia de una industria que en realidad no operaba, al menos en el volumen que reportaba al Banco Central, para obtener así fraudulentamente el incentivo de los CAT (Res: 200201292).

En la sentencia de apelación se aprecia cómo, además de la ausencia real de estructura de soporte a las exportaciones consignadas, también se incurrió en la falsificación de la firma de un funcionario de la agencia de carga de los conocimientos de embarque o Bill of Landing en inglés (BL) y se duplicaron los mismos y con ello "claramente se aprecia la maniobra engañosa para fingir las exportaciones de productos inexistentes, ya que (...) se usaron números de $B L$ que correspondían a otras exportaciones que no guardan relación alguna con MAREX S.A. y que habían efectuado otras empresas" (Res: 2002-01292).

Agrega la sentencia que "Estas maniobras fueron posibles, gracias a la ausencia de controles cruzados efectivos entre las entidades supervi- 
soras (...) y ello dio pie a que se encontraran portillos para lograr un enriquecimiento ilícito mediante estos bonos fiscales". La sentencia finaliza declarando sin lugar el recurso de casación al indicar como "(...) las operaciones bancarias figurativas que se realizaron, en realidad eran movimientos meramente formales para efectos contables e inducción a error, ya que el comprobante bancario que obtenía el grupo infractor, hacía pensar al funcionario encargado del Banco Central de Costa Rica que se trataba del pago del comprador extranjero con su concomitante ingreso de divisas, cuando lo que sucedía era lo opuesto, se trataba de un hábil mecanismo financiero placebo que no deparaba ninguna utilidad al Estado, sino todo lo contrario servía para defraudarlo por sumas millonarias" (Res: 2002-01292).

Otro caso de larga memoria entre los actores de comercio exterior es la estafa cometida con la supuesta exportación en volúmenes falsamente consignados de cálculo biliar bovino a los mercados estadounidenses y panameño. La sentencia n. ${ }^{\circ}$ 341-2007 del Tribunal Contencioso Administrativo confirma la decisión de COMEX de iniciar un procedimiento administrativo en contra la empresa Polibiótica Sociedad Anónima y suspender el otorgamiento de los CATs. Según establece el proceso ordinario tramitado ante el Juzgado de lo Contencioso Administrativo y Civil de Hacienda de la empresa denunciante contra el Estado, el problema surge a raíz de facturas cuestionadas por el hecho de que los CATs se otorgaron al producto de exportación "cálculo biliar" pero en la documentación presentada ante COMEX y la DGA el exportador consignaba el producto como "cálculo biliar bovino diluido en jugo biliar". En la sentencia ante este Juzgado, el denunciante argumenta que ambas presentaciones no alteran el producto y que no son dos productos exportados sino uno sólo. La Sentencia del Juzgado Contencioso Administrativo nos aclara este rubro indicando que se había cometido el delito de estafa frente a la demostración de los siguientes hechos:

... no obstante, de lo acreditado se obtiene: a.- que no es posible producir cálculo biliar en un laboratorio; b.- los datos de producción a nivel nacional y la información de los mataderos o empacadores de carne que constan en el expediente, están muy por debajo de los 90 426,00 gramos que la demandante consignó en las facturas de exportación, c.- no se presentaron documentos fehacientes de las compras del producto. Entonces, ¿de dónde obtuvo la actora los 90 426,00 gramos que dice exportó? La única conclusión posible es que el peso lo constituía en su mayor parte, el jugo biliar en que se diluyó el producto. En otras palabras, no se exportó "cálculo biliar" en que se utilizó como medio de conservación "jugo biliar", sino que la mayor parte del peso exportado corresponde al jugo $\underline{\text { biliar, que no está incluido dentro del con- }}$ trato de exportación firmado con el Estado (Tribunal Contencioso Administrativo, sentencia n. ${ }^{\circ}$ 341-2007) (el subrayado es de la autora).

\section{Delitos económicos relacionados con la administración del comercio}

El sistema integral de administración de comercio es una función compartida de múltiples actores, que regulan conductas en diferentes áreas temáticas. Bajo ese esquema, varios ministerios -entre los cuales están Agricultura, Salud, Economía y Hacienda (DGA) - entrelazan funciones con el Ministerio de Comercio Exterior (COMEX), rector de la negociación y administración de todos nuestros acuerdos comerciales. El diseño de este entorno institucional de administración del comercio exterior ha sido creado con competencias, por vía legal, a diferentes entidades para 
que administren áreas temáticas específicas del comercio exterior.

En cada una de las funciones de este entramado institucional se protegen diferentes bienes jurídicos, como el debido ingreso fiscal por concepto de aranceles, la salud pública y fitosanitaria, la producción nacional, los derechos del consumidor a inocuidad y calidad debida. De ahí que las violaciones al buen desempeño del comercio se den en diferentes ámbitos, atendidos por diversas entidades, lo que hace sumamente rico y complejo su análisis.

\section{Ilustración de los delitos penales económicos en el área temática de normas de origen, como parte de los delitos aduaneros: el Caso Helados Sarita}

La obligación tributaria aduanera se traduce en el ingreso y egreso de bienes del territorio nacional con una serie de efectos jurídicos, como la presentación de permisos o autorizaciones (como por ejemplo la autorización del MAG del ingreso de mercancías reputadas libre de plaga y enfermedades) o el pago de tributos a la importación o exportación.

La Ley General de Aduanas (LGA) define en su artículo 53 la obligación tributaria aduanera como "... el vínculo jurídico que surge entre el Estado y el sujeto pasivo por la realización del hecho generador previsto en la ley" (p. 32), constituida por los tributos exigidos a la hora de la importación y exportación de mercancías.

En el artículo 55 de la LGA se establece que el "... hecho generador de la obligación tributaria aduanera es el presupuesto establecido por la ley para tipificar el tributo y cuya realización origina el nacimiento de la obligación.... La obligación tributaria aduanera está vinculada al acto administrativo donde el hecho generador depende de la declaración voluntaria del usuario donde estipula la aplicación de un régimen aduanero específico. Una vez aceptada la declaración aduanera, se genera una obligación legal de pagar tributos en frontera.

Los delitos típicamente aduaneros son el contrabando y la defraudación fiscal aduanera, tipificados por la LGA en las secciones I y II del Capítulo I, del Título X. Sin embargo, la inserción de Costa Rica al comercio exterior y las posteriores negociaciones de tratados de libre comercio y bloques económicos regionales han incluido en esta lista las violaciones a las normas de origen, como acción ilegal vinculada al proceso de importación aduanera.

Las reglas o normas de origen establecen, vía negociación bilateral o regional, cuales son las condiciones y requisitos que deben cumplir los productos para beneficiarse de una preferencia arancelaria, bajo un determinado bloque regional (sea TLC o Unión Aduanera). Barahona y Garita establecen que la consignación de un origen diferente de una mercancía, o sea, un cambio de origen en la declaración aduanera, responde a"... el hecho de que el monto de los impuestos en aduanas varía en algunos casos según el origen de la mercancía; se incurre en este delito cuando se declara en aduanas un origen por el cual se tendrían que pagar menos impuestos que por el origen real de la mercancía" (Barahona y Garita, p. 172).

Desde los años 60, los países del istmo centroamericano han buscado la integración en el ámbito económico. Parte inherente de esta integración es la posibilidad de comercializar productos, de forma intrarregional, sin el pago de aranceles de importación. Esa libre circulación de mercancías es una preferencia de acceso al mercado regional centroamericano con respecto a los productos que ingresan de terceros países. Para que los productos centroamericanos gocen de esa preferencia deben ser considerados "originarios". Hacemos la acotación de que esa condición no se extiende a 
los productos de otros países por el mero hecho de "provenir" un país centroamericano, en razón de tránsito, sino que para poder circular libremente por la región deben cumplir necesariamente con la norma de origen que les confiere ese estatus.

En Costa Rica, la entidad responsable de verificar el origen de las mercancías es la Oficina de Verificación de la Dirección General de Aduanas, adscrita al Ministerio de Hacienda y Crédito Público.

Antecedentes del caso de Helados Sarita: en este caso se realizaron importaciones de helados de la empresa guatemalteca Sarita que fueron declarados como originarios de Centroamérica en los documentos de importación para ingresar a Costa Rica, lo que significa, que se declara cumplimiento de las reglas de origen convenidas por los países centroamericanos para ser considerados como "Productos Guatemaltecos hechos en Centroamérica". En consecuencia, esas importaciones no habían estado sujetas al arancel de importación, ya que gozaban de libre circulación, como casi todo producto centroamericano.

En 2002, la Cámara de Productores de Leche de Costa Rica presentó una denuncia contra los helados Sarita, producidos en Guatemala y que gozaban, hasta el momento, de la posibilidad de ingresar al país sin pagar arancel, al ser considerados productos centroamericanos, por cumplir con la norma de origen, en cuanto a la utilización de leche en polvo centroamericana como insumo en su producción.

La denuncia fue presentada ante la Oficina de Verificación y planteaba en términos de duda razonable el origen de los "Helados varios sabores", con base en una inspección de planta de Sarita S.A. donde se señalaba que el insumo "leche en polvo" provenía de terceros países, como Nueva Zelanda, Estados Unidos y Cana- dá. Si el resultado de la investigación demostraba que esos helados se habían introducido al país sin el pago correspondiente de arancel por no ser "centroamericanos", Costa Rica tenía el derecho legítimo de imponer el arancel en frontera correspondiente a productos lácteos que era del $65 \%$.

La competencia para conocer estos casos recaía, y recae todavía, en la Oficina de Verificación adscrita a la Dirección General de Aduanas (DGA), a la que corresponde la competencia de verificar si un producto goza de la posibilidad de ingresar a nuestro país con el beneficio de una norma de origen, que para el caso en estudio, debía calificar al producto como "producto centroamericano", conforme a los requisitos establecidos en la correspondiente normativa regional.

La denuncia se presentó bajo el procedimiento de verificación de origen de las mercancías establecido en el Reglamento Centroamericano sobre el Origen de las Mercancías de 1998, que permitía iniciar una investigación bajo la premisa de "duda razonable". En este caso, la duda razonable se sustentaba en que la Certificación del MAG costarricense indicaba que la empresa reconocía importaciones de leche en polvo provenientes de Canadá, Estados Unidos y Nueva Zelanda.

Legislación aplicable y entidad competente: el procedimiento de verificación de origen de las mercancías para este caso estaba establecido en el Reglamento Centroamericano sobre el Origen de las Mercancías de 1998. Este procedimiento regional establecía que, en caso de duda razonable, la Oficina de Verificación de Origen de la DGA debía proceder a revisar el origen del producto, para así determinar si era aplicable la preferencia que le permitía libre ingreso al país (léase arancel cero) o si procedía la imposición del arancel correspondiente a un 
tercer país que no gozaba de la preferencia de origen que, para este caso, era del 65\%.

Delitos penales económicos en el área temática de normas de origen: la infracción de la norma de origen implica que el producto "centroamericano" ingresa sin pago de arancel, sin cancelar el 65\% de arancel en frontera, que en realidad le compete al no cumplir la norma de origen que lo exime. Esto no solo puede causar daño al sector productivo lácteo, que de hecho es el quejoso en este caso, sino, además, al Estado porque la infracción de la norma de origen es una clara evasión fiscal. Si el producto no cumple la norma de origen que le exime, se le considera importado de un tercer país y no goza del arancel preferencial que le corresponde si fuera de "origen centroamericano", como parte de la producción integrada en un mercado común regional.

La norma de origen que otorga "origen centroamericano" al producto señala que el insumo de leche y en este caso, leche en polvo, tiene que ser regional, es decir, que la leche en polvo utilizada en su fabricación tiene que ser de Guatemala, Honduras, El Salvador, Nicaragua o Costa Rica. Si se cuestiona que la leche en polvo utilizada en la fabricación del producto es de un tercer país, entonces no califica como "producto centroamericano" y no tiene derecho a beneficiarse de la norma de origen que exime de tributo.

Como comentó la autora hace exactamente una década, "es la primera vez que se utiliza el procedimiento del Reglamento y si se logra demostrar que efectivamente estaban incurriendo en esa conducta, será positivo para incrementar el respeto a las normas que se negocian y la protección a la producción legítimamente centroamericana"(Govaere, 2003).

Se debe tener presente que más allá del delito de tributación aduanera y la consiguiente defraudación al fisco costarricense que deja de percibir ingresos en concepto de aranceles, el cambio de una norma de origen puede lesionar a un sector productivo nacional, como en el caso de Helados Sarita. Es por eso que la Cámara de Productores de Leche tenía legitimidad activa para presentar la denuncia contra la importación de Helados Sarita bajo la normativa centroamericana, en caso de duda razonable sobre el verdadero origen regional de la mercancía.

Caso: las autoridades aduaneras costarricenses, posteriormente a las importaciones y con base en la denuncia presentada por el gremio lechero costarricense, iniciaron un procedimiento de verificación del origen de esos helados que produjo una resolución administrativa de la Dirección General de Aduanas. La resolución RES-TLC-DNP-DV-001-2003 del 12 de febrero de 2003 denegó otorgar trato arancelario preferencial a los helados al determinar que el helado de varios sabores del inciso arancelario 2105.00.00.99 no calificaba como originario de Guatemala, por no cumplir con el cambio de clasificación arancelaria estipulado en la regla específica de origen del Anexo de ese Reglamento. Eso implicó los helados Sarita debían pagar aranceles al considerar que los helados contenían leche en polvo producida fuera de la región.

Desde el ángulo técnico, el caso en discusión implica la aplicación e interpretación de la regla específica de origen aplicable a helados, en relación con la regla accesoria "De Minimis", ya que en la producción de los helados Sarita importados en Costa Rica se había utilizado leche en polvo no originaria, eso es, procedente de un tercer país no Centroamericana.

Esta resolución fue apelada ante el Tribunal Aduanero Nacional (Sentencia n. ${ }^{\circ}$ 188-2004. Tribunal Aduanero Nacional) que confirmó la actuación por parte de las autoridades aduaneras costarricenses: 
... ha quedado demostrado en expediente que las mercancías objeto de verificación no cumplen con las regulaciones necesarias para tenerla como originaria, al no cumplir con la regla específica de origen, toda vez que se utilizaron materias primas no originarias no permitidas por esa regla y no procediendo tampoco la aplicación de la regla de minimis... (Sentencia n. ${ }^{\circ}$ 1882004. Tribunal Aduanero Nacional).

Independientemente de la recién citada decisión del tribunal en alzada, este caso fue llevado a un procedimiento de solución de controversias aplicando los mecanismos negociados por los países Centroamericanos para dilucidar esos conflictos, fuera de los tribunales administrativos o judiciales nacionales. El fallo del tribunal arbitral fue el primero en aplicar el Mecanismo de Solución de Controversias Comerciales entre Centroamérica, adoptado mediante Resolución 106-2003 (COMIECO- XXVI) de 17 de febrero de 2003, en vigor desde el 17 de marzo de 2003. El fallo del caso a nivel de panel centroamericano fue desfavorable para Costa Rica.

Paralelamente a la evolución legal de este caso, una vez que la DGA costarricense dictaminó que debía elevarse el arancel al producto bajo investigación, el caso degeneró en una "guerra comercial", con la aplicación de medidas de retorsión por parte del gobierno guatemalteco, que consideró adecuado el inicio de una investigación de oficio contra los productos lácteos costarricenses, específicamente, todos los productos lácteos exportados a Guatemala por la Cooperativa Dos Pinos. Se elevaron los aranceles al universo de lácteos exportado por Dos Pinos bajo el señalamiento de la autoridad guatemalteca de que no cumplían, cada uno de ellos, la norma de origen correspondiente bajo el Reglamento Centroamericano. Como se indicó arribo, el caso se revisó, posteriormente, a través del mecanismo de solución de controversias centroamericano, con el resultado de un fallo desfavorable para nuestro país. Este fallo considera que el procedimiento observado por la Oficina de Verificación no contempla todos los elementos a considerar, específicamente la regla de "de minimis" y considera a los productos Helados Sarita como originarios de la región, en detrimento del fallo del Tribunal Aduanero Nacional.

\section{Medidas sanitarias y fitosanitarias: el caso de importaciones de cerdo de Canadá con carencia de certificaciones vigentes de establecimientos comerciales de origen}

Las medidas sanitarias y fitosanitarias son medidas aplicadas por los Miembros de la OMC para proteger la salud y la vida de los animales y preservar los vegetales de los riesgos resultantes de la entrada de plagas, enfermedades y organismos patógenos o portadores de enfermedades, y para proteger la vida y la salud de las personas de los riesgos dimanantes de la presencia de aditivos, contaminantes, toxinas u organismos patógenos en los productos alimenticios o las bebidas y sus empaques. Esto último se conoce bajo el término técnico de "inocuidad de alimentos", que expresa la necesidad de que los productos alimenticios sean aptos para el consumo humano.

El Acuerdo de Medidas Sanitarias y Fitosanitarias establece que los países Miembros "tienen derecho a adoptar las medidas sanitarias y fitosanitarias necesarias para proteger la salud $y$ vida de las personas y de los animales o para preservar los vegetales, siempre que tales medidas no sean incompatibles con las disposiciones del presente Acuerdo" (Textos JurídicosResultados de la Ronda Uruguay de Negociaciones Comerciales Multilaterales, p. 75). 
El caso que analizaremos a continuación ilustra la potestad que tienen los Miembros de la OMC de adoptar medidas para proteger su territorio en contra de importaciones que atenten contra su estatus sanitario y fitosanitario. La importación de productos alimenticios de terceros países debe necesariamente contar con una inspección previa de su establecimiento o planta de origen por parte de las autoridades costarricenses para determinar la idoneidad del producto, antes de ser realizada la importación. Debe entonces contar la importación a nuestro país con una certificación de planta, vigente al momento de dicha importación, y compete, por otro lado, a las autoridades domésticas, autorizar y cerciorarse de que las importaciones sean realizadas solamente cuando las mismas cumplen dichos requisitos.

En el caso que analizaremos existe clara omisión en el cumplimiento de su deber, por parte de la Dirección indicada, siendo este un delito de carácter público por incumplimiento del deber de vigilancia. Como veremos a continuación, no siempre nuestras autoridades han demostrado completa consciencia de la importancia de respetar estas normas, en detrimento de posibles daños a la salud y vida de personas, animales y preservación de vegetales nacionales frente a productos importados con problemas sanitarios o fitosanitarios, en detrimento de la salud pública, el estatus sanitario y fitosanitario del país, con daño posiblemente contaminante de la producción nacional, así como perjuicio de la capacidad exportadora del país, al reputarse importando productos con posibles plagas.

Antecedentes: desde octubre del 2003 hasta febrero del 2004 se permitió autorización de ingreso de la carne de cerdo proveniente del Canadá, con la certificación vencida en detrimento de la legislación aplicable en Costa Rica.
Legislación aplicable y entidad competente: el procedimiento de evaluación y aprobación de productos y subproductos de origen animal importados por Costa Rica se encontraba regulado bajo el Decreto Ejecutivo n. ${ }^{\circ} 21858-$ MAG de 28 de setiembre de 1992, reformado por Decreto n. 31105-MAG de 9 de diciembre de 2002. Allí se establecía que a Costa Rica solo debían ingresar productos y subproductos de origen animal cuyas plantas o establecimientos hubieran sido previamente evaluados y aprobados por la Dirección de Salud Animal del Ministerio de Agricultura y Ganadería.

En Costa Rica, el área temática concerniente a medidas sanitarias y fitosanitarias está determinada como competencia legal del Ministerio de Agricultura y Ganadería (MAG) y para el caso particular en estudio involucra la Dirección de Salud Animal.

Caso: en 2002, funcionarios de la Dirección de Salud Animal habían realizado las correspondientes "visitas de inspección" a una serie de plantas que procesan cerdo en Canadá y a partir de octubre del mismo año, se acordó autorizar la exportación de dichas plantas hacia Costa Rica, estableciendo el plazo de vigencia de 1 año. El año siguiente, la Dirección de Salud Animal aprobó el ingreso de carne proveniente de plantas cuya inspección había vencido en meses anteriores, bajo la consideración de que dicho acto no implicaba, "especiales riesgos para nuestro país y su salud animal, llegándose a la conclusión de que aunque era necesario reinspeccionar las plantas y detener cualquier solicitud nueva de ingreso a nuestro país de carne de cerdo como medida inmediata, esa omisión implicaba un riesgo mínimo" (jsic!). Posteriormente, en abril 2004, vía Decreto Ejecutivo, el MAG amplió a posteriori el plazo de aprobación de las plantas o establecimientos de exportación de uno a tres años, mientras, previa a esta extensión se había seguido importando, sin respaldo legal. 
Delitos penales económicos en el área temática de medidas sanitarias y fitosanitarias:_en 2004 se interpuso recurso de amparo de varios agremiados de la Cámara Costarricense de Porcicultores contra las importaciones de carne de cerdo bajo el TLC con Canadá, con permisos de inspección de planta vencidos y de forma "provisional" mientras se realizaba la consiguiente inspección de planta, en incumplimiento de los requisitos sanitarios vigentes bajo la legislación costarricense.

El recurso de amparo resuelto por la Sala Constitucional en resolución 2005-04290 manifiesta que "... el recurrido y su antecesor han autorizado desde octubre del dos mil tres la importación de carne de cerdo procedente del mercado canadiense, a pesar de que los respectivos sistemas de inspección veterinaria de plantas o establecimientos procesadores de cerdos no han sido evaluados ni aprobados por el Departamento de Salud Animal del MAG, según lo exige el Decreto Ejecutivo 21858-MAG del (...) de mil novecientos noventa y dos, reformado mediante Decreto Ejecutivo 31105-MAG del nueve de diciembre del dos mil dos" (Expediente: 04-001818-007-CO/ Res: 2005-04290) (Como hechos se establece que dicha importación ha causado daño al sector productivo porcino, afectando los precios de mercado del producto nacional).

Ya la Sala Constitucional había declarado inconstitucional un caso similar, bajo idénticas premisas. El Voto S.C. 4634-03 había ya indicado cómo el Ministerio de Agricultura, había violentado la misma normativa, bajo el mismo TLC, y había:

... actuado inconstitucionalmente al autorizar la importación temporal de cerdos de plantas procesadoras del Canadá que no estaban aprobadas por ese Ministerio, violentando con ello el sistema de inspección, aprobación y control establecido en el Decreto Ejecutivo 21858-MAG (...) la Sala Constitucional indicó en tal ocasión que el sistema de inspección, aprobación y control que establecía dicho Decreto tenía una evidente función protectora de valores que son de orden fundamental, como la salud de la población, el bienestar de los consumidores, el estímulo a la producción nacional (que en este caso se traduce en garantías para los porcicultores que prevengan la introducción de enfermedades que imposibiliten su producción), y la economía del país (artículos 21, 46 y 50 de la Constitución Política) (Énfasis de la autora).

La Sala reitera esas mismas consideraciones, citadas supra, condenando al Estado al considerar que su actuación, una vez más, constituye:

....un acto que pone en riesgo la salud de la población, el bienestar de los consumidores, y el estímulo a la producción nacional invocados por el recurrente, porque permitió el ingreso al país de productos y subproductos de origen animal sin cumplir los requisitos sanitarios establecidos, en este caso la necesaria reinspección de las plantas de donde procede la carne, dentro de los límites temporales que exigía en ese momento el ordenamiento jurídico y estando, en consecuencia, la certificación vencida. Nuevamente, la autoridad recurrida asume una discrecionalidad peligrosa para los bienes jurídicos en juego" (Énfasis de la autora).

La Sala reitera en este caso, que la protección sanitaria y fitosanitaria, como competencia de esta entidad estatal es una evidente función protectora de valores transcendentales como lo son la salud de la población, el bienestar de los consumidores y el estímulo a la producción nacional", estimando que la conducta de la autoridad estuvo permeada por una peligrosa discrecionalidad para los bienes jurídicos tute- 
lados, donde resulta lesionado el principio de protección de la confianza legítima del consumidor, del productor nacional y de la seguridad alimentaria, sanitaria y fitosanitaria de un país.

\section{La competencia del MEIC sobre la protección del consumidor a través de la verificación de mercados: el caso Mazola}

Dentro del sistema articulado de instituciones que coparticipan, como contrapeso defensivo, bajo el modelo actual de apertura de mercados se encuentra la legítima defensa de los consumidores frente a las mercancías importadas, para éstas cumplan con los requisitos sanitarios, de inocuidad y de etiqueta exigidos por la normativa internacional y nacional. La legislación nacional de defensa del consumidor parte del principio de otorgar al consumidor debida tutela y legítima protección frente a los productos del mercado.

Dentro del Ministerio de Economía, Industria y Comercio, la Dirección de Apoyo al Consumidor consta de un Departamento con competencias específicas para la verificación del mercado costarricense, que vela por la idoneidad de las mercancías ofrecidas al consumidor, sea de origen doméstico o extranjero. Es entonces competencia y responsabilidad del MEIC velar por la seguridad de nuestros consumidores y verificar que tanto los productos nacionales como los importados cumplan con los requisitos de inocuidad, etiquetado y calidad.

Esta es la cara olvidada y poco conocida de nuestra apertura comercial: la protección interna de nuestro consumidor de que los productos importados cumplan con requisitos tanto de inocuidad como de calidad, y que además no induzca al consumidor en error por incumplimiento doloso de las normas de etiquetado o por publicidad engañosa.
La inducción en error al consumidor con relación a los productos importados y domésticos que circulan en el territorio nacional son elementos lesivos de la confianza del consumidor en el ordenamiento económico. En el caso "Mazola" (2007-2010), se examina el impacto negativo y la conducta dolosa de comercializadoras de productos importados bajo esta marca registrada como tal en Honduras y, que no tiene relación con la marca americana. Este es un ejemplo de actuación dolosa de los comerciantes importadores y de las medidas de elusión utilizadas para la evasión de la normativa vigente de defensa al consumidor.

Antecedentes La presentación de una denuncia que involucra la comercialización de aceites vegetales de origen hondureño en el mercado costarricense fue punto de partida para que el Departamento de Políticas y Apoyo al Consumidor (DEPAC) realizara una verificación en el mercado a través de un muestreo estadístico de los productos "Aceite Mazola" en sus diversas presentaciones. Posteriormente, el Laboratorio Costarricense de Metrología (en adelante LACOMET), dependencia del MEIC, en el oficio n. ${ }^{\circ}$ 421-2007, del veinte de setiembre del dos mil siete, realizó los análisis de las muestras recabadas por el DEPAC.

Este caso involucra a los productos comercializados bajo la marca MAZOLA, producidos en Honduras. El voto 042-09 del 19 de Enero del 2009 ordenó la suspensión de la comercialización en el territorio nacional del aceite vegetal de la marca Mazola Natural Blend. Este voto de la Comisión Nacional del Consumidor ordenó a la denunciada Comercial Dinant de Costa Rica S.A. " ... abstenerse de la comercialización de dicho producto y proceder a la rectificación de la información en cuanto a la utilización de la representación gráfica de la mazorca de maíz y la declaración de aceite de maíz en la lista de ingredientes". 
El voto 042 del 2009 demostró que el ACEITE MAZOLA NATURAL BLEND y el ACEITE MAZOLA PLUS con Omega 3 NATURAL BLEND, importados de Honduras, no contenía el porcentaje publicitado en su etiqueta de aceite de maíz y que, más bien, el aceite de palma representaba entre un 70 a $80 \%$ del contenido total del producto. En detrimento de la información contenida en sus etiquetas donde se indicaba un producto como de $100 \%$ de aceite de maíz, en realidad, una prueba de laboratorio probó que su contenido era principalmente aceite de palma.

Estos productos se comercializaron libremente en nuestro país desde que se presentó la denuncia en Junio 2007 hasta el voto 042 de Setiembre del 2009. El recurso de revocatoria demostró que ambos productos, comercializados bajo dos presentaciones diferentes, eran el mismo producto y contenían la misma formulación según el registro del Ministerio de Salud. Por ello, el voto 042 del 2009 estimada válida la suposición de que ambos productos se comercializaban en el mercado costarricense bajo una declaración falsa de su contenido, que a diferencia de su etiquetado no era aceite de maíz sino en realidad, una mezcla que contenía en mayor proporción de aceite de palma.

Legislación aplicable: La Ley de Promoción de la Competencia y Defensa Efectiva del Consumidor, Ley n. 7472 , y concretamente la infracción del artículo 34 incisos b) y m), por falta de información. También se aplica el decreto ejecutivo n. 26012 MEIC-S de etiquetado de alimentos preenvasados, en específico, por incumplimiento de reglamentación técnica de acatamiento obligatorio.

\section{Ilustración de delitos penales económicos en el área temática de defensa al consumidor}

El Caso MAZOLA ilustra el incumplimiento por parte de comercializadoras hondureñas de aceites vegetales importados bajo marcas supuestamente reconocidas que se comercializaron en Costa Rica violando la legislación de etiquetado vigente, poniendo en clara desventaja a la industria nacional que sí cumplía a cabalidad estas normas e induciendo a engaño al consumidor porque declaran falsamente ingredientes o beneficios nutricionales.

Indica el Voto n. 042-09 que la denuncia se sustenta en el deber de información de parte del productor y el comerciante hacia el consumidor y señala que:

... es importante recordar que el artículo 46 de la Constitución Política dispone una tutela amplia para los derechos de los consumidores, debiendo el Estado coordinar esfuerzos, para hacer efectiva dicha tutela (...) Los consumidores y usuarios tienen derecho a la protección de su salud, ambiente, seguridad e intereses económicos; a recibir información adecuada y veraz; a la libertad de elección, y a un trato equitativo. El Estado apoyará los organismos que ellos constituyan para la defensa de sus derechos (Comisión Nacional del Consumidor, Voto n. ${ }^{\circ}$ 042-09).

El voto hace referencia a la competencia legalmente dada a la Comisión Nacional del Consumidor de tutelar y velar por el cumplimiento de los reglamentos técnicos de acatamiento obligatorio de bienes y servicios dispuestos al consumidor final. El voto hace una reseña a la aplicación doctrinaria en este caso citado, del "Principio de Veracidad", como apego a la verdad en la información que se le brinde al consumidor, evitando "inducir a error al consumi- 
dor, ni de manera directa, ni por ambigüedad, omisión o exageración" (Comisión Nacional del Consumidor, Voto 042-09).

El Voto 042-09 resalta, para el caso en estudio, cómo la información presentada al consumidor debe ser "... clara y veraz, (...) debe enterar al consumidor de la naturaleza, la composición, el contenido, el peso, las características de los bienes y servicios, el precio y cualquier otro dato determinante y toda esta información debe estar en idioma español (artículo 34 inciso b) de la ley de cita)" Con relación específicamente al etiquetado, el artículo 43 del reglamento a la ley 7472 establece el deber de brindar información real al consumidor, bajo los siguientes términos"(...) En aplicación de las normas de etiquetado (...) se debe informar sobre la naturaleza, la composición, el contenido, el peso cuando corresponda, las características de los bienes y servicios; así como cualquier dato determinante (...)".

El voto 042 del 2009 indica que el ACEITE MAZOLA NATURAL BLEND y el ACEITE MAZOLA PLUS con Omega 3 NATURAL BLEND, presentación bajo las cuales se comerciaba la marca MAZOLA registrada en Honduras, no contenía el porcentaje de aceite de maíz indicado en el producto y que era más bien, una mezcla de aceites donde predominaba el aceite de palma. En una de sus presentaciones, la información contenida en la etiqueta decía que el producto estaba hecho de 100\% aceite de maíz, lo que se refutó en los laboratorios del Estado.

Frente a la denuncia planteada en la DEPAC, el Voto 042-09 consigna que "... el etiquetado del producto "Aceite MAZOLA Natural Blend" se presta para confundir al consumidor por cuanto "(...) a) Se menciona expresamente las palabras "100\% Pure" o "100\% Pura", cuando en realidad el producto es una mezcla de aceites vegetales...." (Voto 042-09). Detalla la autoridad competente que la utilización del término
"Pura" es permitida en tanto "...no induzca a error al consumidor, puesto que la información del etiquetado, debe siempre ajustarse al principio de veracidad contenida en la publicidad, entendida ésta como el empaque de los productos en cuestión."

Adicionalmente, para el caso de marras, la información estaba en la parte frontal del producto denunciado, en inglés y sin traducción alguna. Estimó la Comisión que la información "cholesterol free 100\% Pure MAZOLA Natural Blend Og Trans Fat. 0 g Carbs" en inglés y sin traducción contraviene el artículo 8.2 del reglamento 26012 que señala "Deberán redactarse en idioma español, cuando el idioma en que esté redactada la etiqueta original no sea en este idioma, en vez de poner una nueva etiqueta podrá emplearse una etiqueta complementaria, que contenga la información obligatoria en el idioma español (Voto 042-09) ".

Establece el Voto 042 del 2009 que, en vista de estas circunstancias:

... un consumidor promedio no tiene cómo verificar esta información, y mucho menos puede con la información consignada, deducir que el producto es 100\% puro en cuanto a la mezcla, ya que la información que detalla la lista de ingredientes al dorso del producto, no indica que los mismos sean 100\% puros. En razón de lo anterior, se configura una falta a la norma técnica en cuanto al idioma y una falta al deber de información.

Agrega el Voto 042-09 que:

...se puede desprender claramente que el ingrediente con mayor presencia en el ACEITE MAZOLA NATURAL BLEND es el aceite de palma africana, del cual predomina en un 70 a 80 por ciento del contenido total, y específicamente, en el caso del aceite de maíz, el mismo no está presente, 
dado que lo que contiene es aroma natural a maíz. En razón de lo anterior, la información consignada en la lista de ingredientes no está acorde con la norma técnica y desde el punto de vista del derecho de información del consumidor, induce a engaño, puesto que destaca como ingrediente el aceite de maíz, mismo que no está presente, y en el contexto de todo el etiquetado analizado en el considerando anterior, es posible que el consumidor interprete que está adquiriendo aceite de maíz, cuando este ingrediente no está presente en el producto.

Por ello, considera el Voto que dicha conducta implica "... desinformar al consumidor de aspectos relevantes para su decisión de consumo...", lo que pesa en las sanciones impuestas por la Comisión, que afirma la comisión de una infracción al artículo 34 incisos b) y m) de la Ley 7472, por falta de información e incumplimiento de lo dispuesto en las reglamentaciones técnicas de acatamiento obligatorio, decreto ejecutivo 26012 MEIC-S de etiquetado de alimentos preenvasados.

El Voto indicado supra impone sanciones pecuniarias a empresa Comercial DINANT de Costa Rica, S.A., de conformidad con el artículo 57 inciso b), de la ley 7472 la multa de $\$ 5$ 170000.00 de colones, equivalente a cuarenta veces el menor salario mínimo mensual contenido en la Ley de Presupuesto Ordinario de la República, el cual al momento de los hechos, dada la gravedad de la omisión de información relevante para el consumidor y por eventual afectación a la salud.

En el Voto analizado además se ordena la rectificación de la información contenida en el etiquetado para que idioma español, se ajuste a los ingredientes contenidos, omitiendo cualquier tipo de información textual o gráfica que
"... pueda confundir al consumidor en cuanto a la naturaleza del producto y, asimismo, deberá el infractor indicar la información relevante respecto a la composición del producto, para que el consumidor cuente con elementos veraces a la hora de tomar su decisión de consumo"

\section{Hechos posteriores al Voto 042-2009}

El Voto 042-09 ordena que los productos sean retirados de las góndolas de los supermercados y la revisión y adecuación del etiquetado del producto. Posteriormente, sin embargo, reaparecieron otras versiones del producto MAZOLA importado de Honduras, con las mismas incoherencias entre la información suministrada para su registro al Ministerio de Salud y su composición real.

Meses después, en evidente desobediencia del voto 042 del 2009, la marca Mazola reaparece en el mercado costarricense, a mediados del 2009, con los productos Aceite MAZOLA Plus renovado. Esta vez, la indicación del etiquetado califica la composición del producto como aceite de linaza, antioxidantes, Omega 3, 6 y 9 (registro sanitario \#2104-A-67897), en lo que el MEIC consideró, claro movimiento para eludir el fallo de su Dirección de Apoyo al Consumidor y seguir vendiendo en Costa Rica, bajo falsas premisas.

Este "nuevo" producto contaba con el mismo registro sanitario de los productos incluidos en el voto \#042-09 y por ello, el Ministerio de Salud los apercibió con orden sanitaria el 26 de Junio del 2009. Sin embargo, la Comercializadora logró que el Ministerio de Salud le otorgara un nuevo registro sanitario ese mismo año.

Adicionalmente, en febrero 2010, aparece otra nueva presentación del producto, esta vez como Aceite Mazola Plus con Linaza con una gran mazorca de maíz en su etiquetado SIN 
REGISTRO SANITARIO y sus ingredientes detaIlan una composición diferente al producto original según registro sanitario \# 2104-A-67897. Se comprobó por estudios de laboratorio, que estas presentaciones de MAZOLA y la composición señalada en el etiquetado tampoco correspondían a su composición real, eludiendo así, de forma continua, la directriz de la Comisión Nacional del Consumidor, en un intento de seguir induciendo en error al consumidor, dañando a una legítimamente comercializada producción nacional y violentando las normativa de etiquetado bajo nuestra Ley General de Salud.

\section{CONCLUSIONES}

Esta novedosa mirada de nuestro comercio exterior, vista bajo el prisma de las violaciones al derecho penal económico, nos ilustra su desempeño y evolución a través de las carencias, duplicidades y muchas veces, abusos del entorno legal e institucional concerniente a las diversas áreas del comercio exterior en Costa Rica.

A través de este novedoso recorrido panorámico, se comprueba como en su génesis, el modelo de apertura comercial estaba ligado a sistemas de incentivos a las exportaciones costarricenses no tradicionales, que bajo la figura de los contratos de exportación y los certificados de abono tributario, tuvieron como contrapartida consecuencias negativas que se tradujeron en delitos de estafa en contra del Estado costarricense. Por otro lado, la administración del comercio en nuestro país, en áreas temáticas administradas por una plétora de institucionales con diversas competencias, ha requerido mejores substanciales en el manejo de los procesos, como consecuencia de abusos o errores cometidos por la Administración Pública o por los usuarios comerciales.

Con esta novedosa mirada, se puede revisar el desempeño de múltiples instituciones como los Ministerios de Economía, Agricultura, Hacienda y Comercio Exterior, en casos que van desde la protección al consumidor con la verificación de mercados hasta importaciones de productos con carencia de certificaciones debidamente vigentes. Estos casos estudiados muestran como el país ha ido sumando a su emblemática trayectoria comercial de apertura de mercados, un aprendizaje adicional, que ha sido muchas veces doloroso, a través de sentencias judiciales, como parte del desempeño de administración del comercio exterior.

\section{REFERENCIAS}

Barahona, J. C. y Garita, R. (2000). Aduanas: competitividad y normativa centroamericana. San José. EUNED.

Comisión Nacional del Consumidor. (2009). Voto 042-2009 a las dieciocho horas diez minutos del diecinueve de enero del dos mil nueve.. Ministerio de Economía, Industria y Comercio. San José. Costa Rica.

Expediente: 99-012302-0042-PE/ Res: 2002-01292 / SALA TERCERA DE LA CORTE SUPREMA DE JUSTICIA. San José, a las nueve horas treinta minutos del veinte de diciembre de dos mil dos.

Herrera, C. y Monge (1990). Las Negociaciones de Costa Rica en el marco del GATT, Serie Comentarios sobre Asuntos Económicos n. ${ }^{\circ}$ 86, Banco Central de Costa Rica, San José.

Expediente: 04-001818-007-CO/ Res: 2005-04290/SALA CONSTITUCIONAL DE LA CORTE SUPREMA DE JUSTICIA. San José, a las dieciocho horas del veinte de abril de dos mil cinco.

Issa E. Khoury, H. (2004). Delitos Económicos. Programa de Modernización de la Administración de Justicia. San José. EDITORAMA.

Govaere, V. (2003). Comentarios sobre diversos acontecimientos relevantes en el marco de nuestro comercio internacional. Revista Derecho y Tecnologías de la Información. Volumen n. 1 . UNED. Recuperado el 1602-2013 en: http://www.uned.ac.cr/redti/documentos/COMENTARIOS\%20SOBRE\%20DIVERSOS\%20 ACONTECIMIENTOS\%20RELEVANTES\%20\%20EN\%20 EL\%20MARCO\%20DE\%20NUESTRO\%20COMERCIO\%2OINTERNACIONAL.pdf 
Govaere, V. (6 de setiembre, 2009). Una apuesta a la esperanza. San José, La Nación.

Govaere, V. (2012). Resultados y Perspectivas del Comercio Exterior en Costa Rica. Revista Nacional de Administración 2 (1), San José. UNED.

Govaere, V. (2014). Recuperado de: http://www.uned. ac.cr/ocex/images/stories/boletines/un_modelo_ exitoso_que_toca_techo_.pdf

Herrero, F. y Monge, G. (2013). Grandes retos de la política tributaria costarricense. Recuperado de: http://documentos.cgr.go.cr/content/dav/jaguar/documentos/ libro_blanco/cap_intro.pdf

Ley General de Aduanas de la República de Costa Rica. Recuperada el 21 de abril del 2013 en: https://www.hacienda.go.cr/NR/rdonlyres/7F869F85-38E3-4720-8643E3B52EAC4C3A/6909/LeyGeneraldeAduanas.htm

Ministerio de Comercio Exterior. (1987) Memoria 19861987. San José, Costa Rica.

Sauma, P. y Trejos, J. D. (s.f). Gasto Público en Servicios Sociales Básicos en América Latina y el Caribe, CEPAL, Recuperado de: http://www.eclac.org/publicaciones/ $\mathrm{xml} / 8 / 4648 /$ costarica.pdf

Sentencia $n .^{\circ}$ 2005-04290 de las dieciocho horas con veintidós minutos del veinte de abril del dos mil cinco.

Sentencia 341-2007 de la Sección Segunda del Tribunal Contencioso Administrativo. Segundo Circuito Judicial. San José, a las catorce horas cuarenta y cinco minutos del veintisiete de julio de dos mil siete.

Sentencia n. ${ }^{\circ}$ 439-01 del veintitrés de abril del dos mil uno del Tribunal de Juicio del Primer Circuito Judicial de San José.

Sentencia n. 188-2004. Tribunal Aduanero Nacional. San José, a las catorce horas y veinte minutos del cinco de agosto de dos mil cuatro.

Organización Mundial del Comercio. (2003). Textos Jurídicos-Resultados de la Ronda Uruguay de Negociaciones Comerciales Multilaterales. Publicaciones Oficiales de la OMC, Ginebra.

Trejos, G. (1985). Constitución Política de Costa Rica: Anotada y Concordada San José, Editorial Juricentro.

Recibido: 5 de setiembre de 2014

Aceptado: 15 de octubre de 2014 